\title{
SECAGEM COM MICRO-ONDAS DE "SNACKS" DE MANDIOCA UTILIZANDO O COZIMENTO COMO PRÉ-TRATAMENTO
}

\author{
L. T. GONÇALVES ${ }^{1}$, N. R. PEREIRA ${ }^{1 *}$, L. A. CAÉ ${ }^{1}$, S. J. FREITAS ${ }^{1}$ \\ ${ }^{1}$ Universidade Estadual do Norte Fluminense Darcy Ribeiro, Laboratório de Tecnologia de \\ Alimentos, Centro de Ciências e Tecnologias Agropecuárias \\ e-mail: nadiar@uenf.br
}

\begin{abstract}
RESUMO
A mandioca é fonte de carboidratos e possui em média $65 \%$ de umidade, por isso, apresenta alta perecibilidade pós-colheita. A secagem é um método de conservação de alimentos e a aplicação de micro-ondas pode reduzir o tempo de secagem quando comparado com o método convencional de secagem com ar quente. A utilização de prétratamentos, como o cozimento, pode interferir no processo e gerar um produto final com melhores características sensoriais e mais próximo do desejado pelo consumidor. Este trabalho avaliou o efeito de diferentes condições de temperatura (40 a $100{ }^{\circ} \mathrm{C}$ ) e tempo de cozimento ( 2 a $10 \mathrm{~min}$ ) em água na cinética de secagem de "snacks" de mandioca com ar quente combinado com micro-ondas $\left(60{ }^{\circ} \mathrm{C}\right.$ e $\left.2,5 \mathrm{~W} / \mathrm{g}\right)$. Os resultados indicaram que a temperatura de cozimento, e consequentes alterações estruturais promovidas nas raízes, apresentou efeito significativo na umidade e atividade de água do produto seco, ou seja, quanto mais elevada a temperatura, maior foi a umidade e atividade de água final. O processo de gelatinização do amido é provavelmente o fator dominante no decréscimo da velocidade de secagem dos produtos, principalmente quando cozidos em maiores temperaturas.
\end{abstract}

\section{INTRODUÇÃO}

A mandioca desempenha um importante papel na dieta dos brasileiros, sendo também utilizada em todo o mundo. É fonte de carboidratos e considerada um alimento de alto valor energético. No entanto, a alta perecibilidade das raízes na pós-colheita e a facilidade de contaminação microbiológica estabelecem barreiras para sua maior utilização. Como o teor de água de um alimento é o principal causador de deterioração por microrganismos, reações químicas e enzimáticas, a utilização de um método de conservação, como a secagem, pode ser eficaz para prolongar seu tempo de vida útil. Em média, frutas e legumes frescos apresentam $80 \%$ de umidade, sendo classificados como alimentos altamente perecíveis (BEZERRA, 2002; ALVES et al., 2005; ORSAT et al., 2007).

Atualmente os produtos desidratados estão sendo amplamente procurados e estudados. A secagem é uma operação na qual ocorre eliminação da água de um material por evaporação ou sublimação, por meio da aplicação de calor com condições controladas e é, provavelmente, o mais antigo método de conservação de alimentos. A secagem permite preservar a qualidade nutricional, gera mais praticidade para o consumidor e aumenta o tempo de utilização com relação ao alimento in natura. A secagem reduz a atividade de água do produto, inibindo assim o crescimento microbiano, diminuindo a atividade enzimática, a velocidade das reações químicas e consequentemente, evita as deteriorações dos 
mesmos (MUJUMDAR, 2000; FELLOWS, 2006).

Apesar da secagem com ar quente ser um método de baixo custo, ela possui vários inconvenientes, tais como baixa eficiência energética, taxas de secagem mais lentas com consequente longos tempos de secagem e menor qualidade do produto final. Neste processo podem ocorrer perdas nutricionais principalmente pelo longo período de exposição do produto ao calor. A aplicação de micro-ondas pode reduzir o tempo de secagem quando comparado com o método convencional de secagem com ar quente. A rápida absorção de micro-ondas pelas moléculas de água favorece a evaporação e difusão de umidade, as quais resultam aumento das taxas de secagem (RAGHAVAN et al., 2005; PEREIRA, 2007; LOPES, 2013)

A utilização de pré-tratamentos, como o cozimento, branqueamento e desidratação osmótica, pode tornar o processo mais eficaz e gerar um produto final com melhores características sensoriais e mais próximo do desejado pelo consumidor. Em alimentos ricos em amido, como é o caso da mandioca, esta etapa de pré-cozimento, pode melhorar a textura e também gerar um produto mais atraente ao consumidor. As alterações estão relacionadas com o rompimento da estrutura celular, redução da permeabilidade da superfície e gelatinização do amido que ocorre durante o cozimento (ANTONIO, 2002; VARNALIS et al., 2001).

$\mathrm{O}$ efeito do pré-tratamento na secagem de fatias de mandioca foi estudado por PEREIRA et al. (2014), onde os autores concluíram que o cozimento sob ebulição por 5 min diminuiu a taxa de secagem em relação à do produto in natura no processo com ar quente $\left(60{ }^{\circ} \mathrm{C}\right)$ combinado com micro-ondas (densidade de potência de 0,7 e $2 \mathrm{~W} / \mathrm{g}$ ). No entanto, o produto pré-cozido apresentou, visualmente, melhor aparência, cor e textura.
Por esse motivo o objetivo principal deste trabalho foi verificar o efeito do cozimento prévio, em diferentes condições de tempo e temperatura, na secagem de mandioca com ar quente e micro-ondas.

\section{MATERIAL E MÉTODOS}

\subsection{Preparo da Matéria-Prima}

Foi utilizada a variedade de raiz de mandioca de mesa Pretinha, proveniente de cultivo na Estação Experimental da UENF-RJ, na ilha Barra do Pomba, no município de Itaocara, Rio de Janeiro, localizado na região Noroeste Fluminense. As raízes foram selecionadas de acordo com as condições de estrutura (tamanho e largura semelhantes) e cultivo (colhidas após 9 meses de plantio em dezembro de 2014). As raízes foram lavadas, sanitizadas por imersão durante 15 minutos em solução de hipoclorito de sódio com $100 \mathrm{mg} / \mathrm{L}$ de cloro ativo. Em seguida, foram descascadas manualmente, cortadas em lâminas de $2 \mathrm{~mm}$ de espessura com auxílio de um fatiador de frios elétrico (Gural, modelo GLP-330, Paraná, Brasil) e depois em pedaços cilíndricos de 25 $\mathrm{mm}$ de diâmetro e $2 \mathrm{~mm}$ de espessura utilizando um cortador cilíndrico.

\subsection{Cozimento}

As amostras foram submetidas ao prétratamento, que consiste no cozimento do material por imersão em água destilada na proporção mássica de 1:5 (amostra:água). O cozimento foi realizado em um becker sobre chapa aquecedora (Fisatom, modelo 752A, série 188033, Brasil) com agitação manual, seguido de resfriamento em água destilada à temperatura ambiente (para interromper o cozimento) e escoamento do excesso de água em papel toalha.

O planejamento experimental fatorial $2^{2}$ com quatro repetições no ponto central foi realizado utilizando como variáveis independentes o tempo e a temperatura de 
cozimento, e como variáveis dependentes os teores de umidade e atividade de água do produto seco, os valores utilizados estão representados na tabela 1 .

Tabela 1 - Modelo do planejamento experimental fatorial $2^{2}$ proposto.

\begin{tabular}{ccccc}
\hline & $\begin{array}{c}\text { Valores } \\
\text { codificados }\end{array}$ & \multicolumn{2}{c}{ Valores Reais } \\
\hline Exp & $\mathrm{T}$ & $\mathrm{t}$ & $\mathrm{T}\left({ }^{\circ} \mathrm{C}\right)$ & $\begin{array}{c}\mathrm{t} \\
(\mathrm{min})\end{array}$ \\
\hline 1 & -1 & -1 & 40 & 2 \\
2 & +1 & -1 & 100 & 2 \\
3 & -1 & +1 & 40 & 10 \\
4 & +1 & +1 & 100 & 10 \\
5 & 0 & 0 & 70 & 6 \\
6 & 0 & 0 & 70 & 6 \\
7 & 0 & 0 & 70 & 6 \\
\hline
\end{tabular}

$\mathrm{T}=$ Temperatura $\left({ }^{\circ} \mathrm{C}\right), \mathrm{t}=$ tempo $(\mathrm{min})$.

\subsection{Secagem}

A secagem a ar quente combinado com micro-ondas foi conduzida em um forno de micro-ondas doméstico (Brastemp, modelo BMC38-A) com $750 \mathrm{~W}$ de potência nominal máxima e cavidade com 38 litros de volume, adaptado a um sistema de ar quente instalado no Laboratório de Tecnologia de Alimentos (LTA/ CCTA/ UENF).

As amostras pré-cozidas foram distribuídas em monocamada em bandejas de polipropileno com tela de fibra de vidro revestida com teflon, e colocadas no equipamento de secagem, no qual foram submetidas à secagem com temperatura do ar de $60{ }^{\circ} \mathrm{C}$ e vazão do ar (medida na saída do tubo de exaustão) de $1 \mathrm{~m}^{3} / \mathrm{min}$ e potência aplicada de $180 \mathrm{~W}$ (densidade de potência de $2,5 \mathrm{~W} / \mathrm{g}$ ). A massa de amostra usada em todos os experimentos foi em torno de $73 \mathrm{~g}$. Todos os experimentos foram realizados durante 30 minutos para acompanhamento da cinética de secagem. As curvas de secagem foram determinadas pelo método gravimétrico, pesando as amostras a cada 5 minutos, com auxílio de balança semi-analítica (Shimadzu, modelo UX4200H, Filipinas). As amostras de mandioca permaneceram por mais 30 minutos no secador (totalizando $60 \mathrm{~min}$ de secagem) para determinação da umidade final em 60 minutos.

\subsection{Umidade}

Foi utilizado o método 925.23 da AOAC (1995) para determinação da umidade das amostras. Três gramas das raízes cozidas e secas $(60 \mathrm{~min})$ foram utilizadas seguindo o método de secagem em estufa a $105{ }^{\circ} \mathrm{C}$ a pressão atmosférica até obter peso constante.

\subsection{Atividade de Água}

A determinação da atividade de água foi realizada a $25{ }^{\circ} \mathrm{C}$ pelo método do ponto de orvalho a temperatura constante por meio do instrumento Aqualab (Decagon, modelo DEW, 4TEV, Estados Unidos).

\subsection{Análise Estatística}

O presente trabalho foi analisado estatisticamente pela metodologia de superfície de resposta (BOX; HUNTER; HUNTER, 1978), usando o programa estatístico STATISTICA 5.5.

\section{RESULTADOS E DISCUSSÃO}

Os teores de umidade e atividade de água das amostras cozidas e secas estão apresentados na tabela 2. Segundo a TACO (2011), mandioca crua e cozida apresentam $61,8 \%$ e $68,7 \%$, respectivamente, de umidade. A mandioca utilizada apresentou teores médios mais elevados, tanto a crua $(63,26$ a $73,65 \%)$ quanto a cozida (70,5 a $80,4 \%)$. A umidade na amostra cozida aumentou, em média, $10,7 \%$. Nas amostras secas os teores médios de umidade foram menores do que 
10\%. Amostras que passaram pelo prétratamento em temperaturas menores, apresentaram menor teor de umidade final.

Tabela 2 - Resultados de umidade (X) e atividade de água (Aw) das amostras in natura, cozidas nas diferentes condições do planejamento experimental e secas durante 60 minutos.

\begin{tabular}{|c|c|c|c|c|c|c|}
\hline $\operatorname{Exp}$ & $\begin{array}{c}\mathrm{X} \text { in natura } \\
(\mathrm{g} / \mathbf{1 0 0 g})\end{array}$ & $\begin{array}{l}X \text { cozidas } \\
(\mathrm{g} / \mathbf{1 0 0 g})\end{array}$ & $\begin{array}{c}\text { X seca } \\
(\mathrm{g} / 100 \mathrm{~g})\end{array}$ & $\begin{array}{l}\text { Aw in } \\
\text { natura }\end{array}$ & Aw cozidas & Aw secas \\
\hline $1(-1,-1)$ & $63,2 \pm 0,4$ & $70,5 \pm 0,3$ & $6,5 \pm 0,6$ & $\begin{array}{c}0,9 \pm 0,0 \\
0,991 \pm\end{array}$ & $\begin{array}{c}0,996 \pm \\
0,002 \\
0,994 \pm\end{array}$ & $0,54 \pm 0,06$ \\
\hline $2(+1,-1)$ & $73,7 \pm 0,7$ & $80,4 \pm 0,4$ & $11,0 \pm 0,3$ & $\begin{array}{c}0,001 \\
0,991 \pm\end{array}$ & 0,002 & $\begin{array}{c}0,65 \pm 0,02 \\
0,344 \pm\end{array}$ \\
\hline $3(-1,+1)$ & $73,6 \pm 0,6$ & $78,8 \pm 0,6$ & $7,19 \pm 0,07$ & 0,001 & $\begin{array}{c}0,9 \pm 0,0 \\
1,001 \pm\end{array}$ & 0,005 \\
\hline $4(+1,+1)$ & $63,6 \pm 0,4$ & $76,88 \pm 0,08$ & $9 \pm 2$ & $0,9 \pm 0,0$ & $\begin{array}{c}0,003 \\
0,995 \pm\end{array}$ & $0,69 \pm 0,07$ \\
\hline $5(0,0)$ & $65,1 \pm 0,1$ & $74,3 \pm 0,2$ & $7,3 \pm 0,5$ & $\begin{array}{c}0,9 \pm 0,0 \\
0,991 \pm\end{array}$ & 0,001 & $0,35 \pm 0,01$ \\
\hline $6(0,0)$ & $66,1 \pm 1,7$ & $76,9 \pm 0,4$ & $9,4 \pm 0,4$ & $\begin{array}{c}0,001 \\
0,9917 \pm\end{array}$ & $0,9 \pm 0,0$ & $0,62 \pm 0,05$ \\
\hline $7(0,0)$ & $67,3 \pm 2$ & $73 \pm 1$ & $7,6 \pm 0,3$ & 0,001 & $0,9 \pm 0,0$ & $0,37 \pm 0,03$ \\
\hline
\end{tabular}

Esse resultado pode ser relacionado com menor absorção de água e grau de gelatinização do amido e maior permeabilidade da estrutura celular quando utilizadas as menores temperaturas de cozimento $\left(40{ }^{\circ} \mathrm{C}\right)$.

Os valores de atividade de água das amostras in natura e cozidas foram superiores a 0,99. Esse valor encontrado é característico de vegetais frescos, o que os torna susceptíveis à deterioração microbiológica. Já os resultados das amostras após a secagem mostram valores mais reduzidos, iguais ou inferiores aos valores estabelecidos para alimentos secos e estáveis que é de 0,6 (BOBBIO; BOBBIO, 2001; DAMODARAN et al., 2010).

Observa-se que o processo de cozimento provocou um aumento no ganho de água representado pelo teor de umidade e atividade de água. A imersão em água quente promoveu o amolecimento dos tecidos vegetais, e facilitou a entrada da água de cozimento para o interior do tecido vegetal. A gelatinização promove uma alteração estrutural no amido, o que muda a estrutura de seus grânulos. O cozimento gerou efeitos que interferiram no comportamento da secagem das amostras (DAMODARAN et al., 2010; SAJEEV et al., 2010; VARNALIS et al., 2001).

O comportamento das amostras durante os 30 minutos de secagem podem ser observados na figura 1 .

Nas secagens das amostras cozidas a 40 ${ }^{\circ} \mathrm{C}$ por 2 ou $10 \mathrm{~min}$, as curvas de secagem apresentaram maior diferença, quando comparado com as outras condições de secagem, como era esperado conforme dados de umidade final apresentados na Tabela 2. 
Figura 1 - Umidade adimensional em base seca $\left(\mathrm{X} / \mathrm{X}_{0}\right)$ em função do tempo de secagem (30 minutos) de mandioca cozida de acordo com o planejamento experimental: (1) temperatura de cozimento de $40{ }^{\circ} \mathrm{C}$, (2) temperatura de cozimento de $70{ }^{\circ} \mathrm{C}$, repetições do ponto central, (3) temperatura de cozimento de $100{ }^{\circ} \mathrm{C}$ e (4) todas as condições do planejamento experimental.
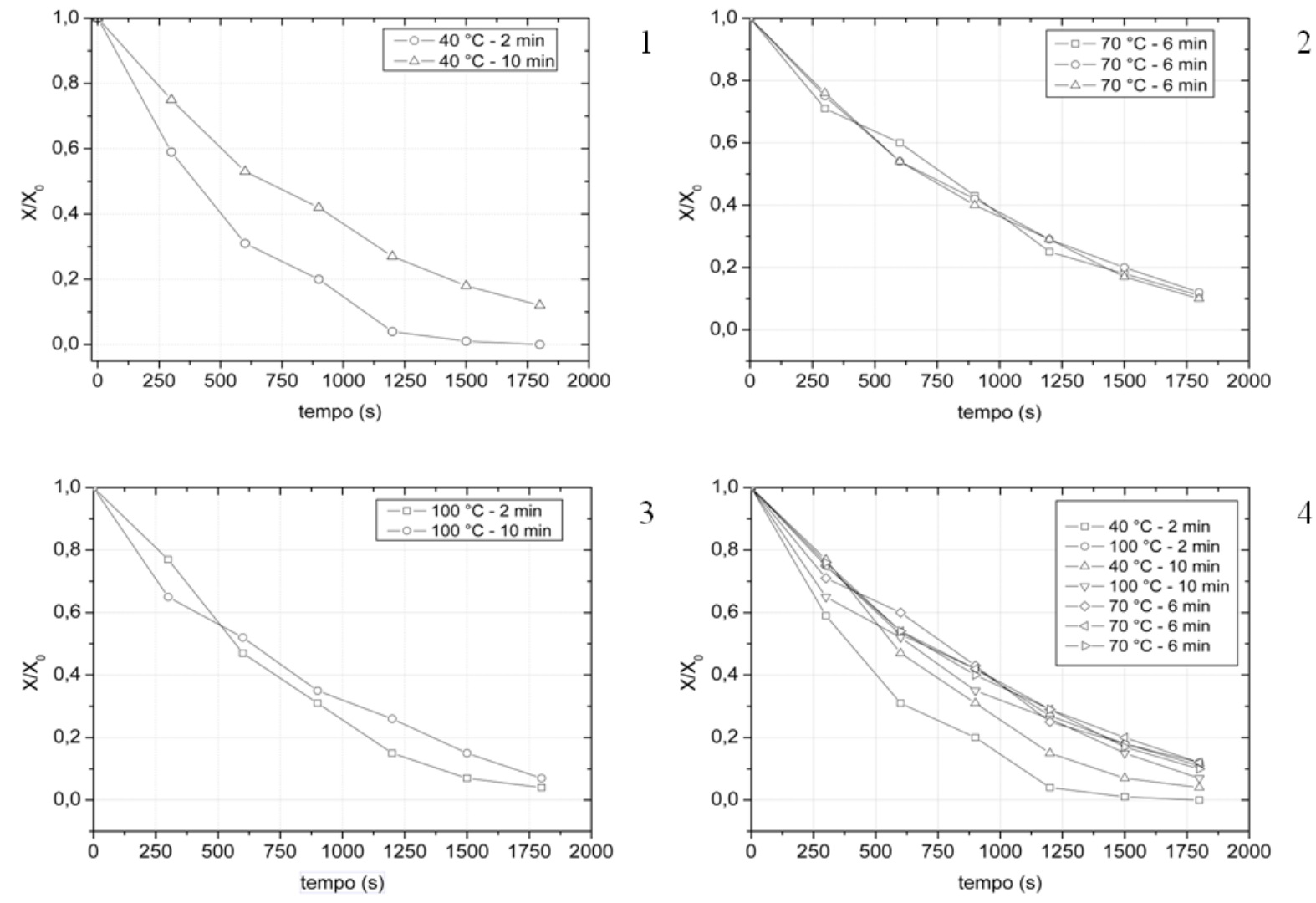

3

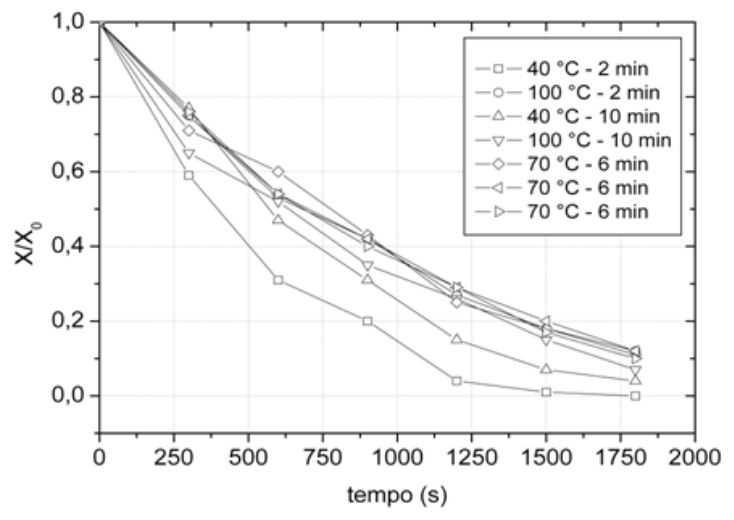

As curvas de umidades adimensional dos três pontos centrais apresentaram boa reprodutibilidade e apresentaram velocidade de secagem inferior à menor temperatura (40 $\left.{ }^{\circ} \mathrm{C}\right)$ de cozimento. Isso pode ser relacionado ao processo de gelatinização do amido, que ocorre entre 45 e $80{ }^{\circ} \mathrm{C}$ na presença de água. Quando o amido gelatiniza, uma espécie de filme é formado em torno das amostras, o que pode dificultar o processo de eliminação da água do interior para a parte externa do vegetal. (BOBBIO; BOBBIO, 2001; FELLOWS, 2006; NWOKOCHA, 2009; PEREIRA, 2010).

As curvas de secagem das amostras cozidas a $70{ }^{\circ} \mathrm{C}$ foram semelhantes quando foi utilizada a temperatura de $100{ }^{\circ} \mathrm{C}$. Neste caso, o fator tempo de cozimento foi a variável que mais influenciou. Quando o tempo foi menor ( 2 minutos) o produto final apresentou menor teor de umidade, similar às amostras cozidas à $40{ }^{\circ} \mathrm{C}$. Essa condição $\left(100{ }^{\circ} \mathrm{C}\right)$ resultou em amostras finais com maiores teores de umidade e atividade de água, em comparação com os demais cozimentos.

Os resultados da análise estatística obtida com os dados experimentais de umidade e atividade de água final (60 min) estão apresentados na tabela 3. Os efeitos foram estimados ao nível de significância de $5 \%$, sendo assim, a variável foi significativa estatisticamente quando $\mathrm{p} \leq 0,05$. 
Tabela 3 - Estimativa dos efeitos sobre a umidade (X) e atividade de água (Aw) final das amostras de mandioca secas.

\begin{tabular}{ccccr}
\hline & & Efeito & \multicolumn{1}{l}{ DP } & \multicolumn{1}{c}{$\mathbf{P}$} \\
\hline & Interação & 8,32 & 0,37 & 0,00 \\
& $\mathbf{T}\left({ }^{\mathbf{}} \mathbf{C}\right)$ & 3,29 & 0,99 & 0,04 \\
$\mathbf{X}$ & $\mathbf{t}(\mathbf{m i n})$ & $-0,51$ & 0,99 & $0,64(\mathrm{~ns})$ \\
& $\mathbf{T} * \mathbf{t}$ & $-1,23$ & 0,99 & $0,30(\mathrm{~ns})$ \\
\hline \multirow{4}{*}{$\mathbf{A w}$} & Interação & 0,51 & 0,05 & 0,00 \\
& $\mathbf{T}\left({ }^{\mathbf{O}} \mathbf{C}\right)$ & 0,23 & 0,15 & $0,22(\mathrm{~ns})$ \\
& $\mathbf{t}(\mathbf{m i n})$ & $-0,08$ & 0,15 & $0,63(\mathrm{~ns})$ \\
& $\mathbf{T} * \mathbf{t}$ & 0,12 & 0,15 & $0,48(\mathrm{~ns})$ \\
\hline
\end{tabular}

$\mathrm{T}=$ Temperatura $\left({ }^{\circ} \mathrm{C}\right), \mathrm{t}=$ tempo $(\mathrm{min}), \mathrm{DP}=$ desvio padrão.

*ns: não significativo.

A análise estatística de efeitos confirma que a variável temperatura apresentou o maior efeito significativo positivo no teor de umidade da mandioca seca a $60 \mathrm{~min}$, ou seja, quanto maior a temperatura utilizada no cozimento maior foi o teor de umidade na amostra seca. O tempo de cozimento teve um efeito secundário, negativo não significativo. Com relação à atividade de água das amostras secas por $60 \mathrm{~min}$, nenhum fator foi estatisticamente significativo, cujos valores estão entre 0,35 e 0,69 . O efeito das variáveis na atividade de água das amostras deveria seguir a mesma tendência do resultado para umidade final. Provavelmente, a variação dos resultados de atividade de água das repetições do ponto central (Tabela 2) interferiram na análise estatística de efeitos, sugerindo que novas análises sejam feitas.

Para verificação da validação do modelo estatístico para umidade, foi realizada a análise de variância (ANOVA). Nesta verificação foram eliminados os parâmetros não significativos. Foi verificada a variância da regressão e falta de ajuste ao nível de significância de 5\%. Foi utilizado o teste $\mathrm{F}$ para o planejamento experimental proposto, cujos resultados estão apresentados na tabela 4.

Tabela 4 - Análise da variância para as respostas umidade com $\mathrm{p} \leq 0,05$.

\begin{tabular}{lcccccc}
\hline \multirow{2}{*}{$\begin{array}{l}\text { Fonte de } \\
\text { variação }\end{array}$} & \multicolumn{6}{c}{ \%Xseca } \\
\cline { 2 - 7 } & SQ & GL & MQ & Fcal & Ftab & R $^{2}$ \\
\hline $\begin{array}{l}\text { Regressão } \\
\text { Resíduo }\end{array}$ & 10,8 & 1 & 10,8 & 11,4 & 6,6 & 0,70 \\
$\begin{array}{l}\text { Falta de } \\
\text { ajuste }\end{array}$ & 2,0 & 3 & 0,6 & 0,4 & 19,1 & \\
$\begin{array}{l}\text { Erro puro } \\
\text { Total }\end{array}$ & 2,7 & 2 & 1,3 & & & \\
\hline
\end{tabular}

$\mathrm{SQ}=$ soma dos quadrados, $\mathrm{GL}=$ graus de liberdade, $\mathrm{MQ}=$ média quadrática, Fcal e Ftab = valor de $\mathrm{F}$ calculado e tabelado respectivamente $\mathrm{e}$ $\mathrm{R}^{2}=$ coeficiente de determinação.

A análise estatística mostrou que $\mathrm{o}$ modelo utilizado para o teor de umidade foi significativo estatisticamente, ou seja, tem regressão significativa (Fcal $>$ Ftab) e tem falta de ajuste não significativa (Fcal < Ftab). No entanto, o modelo da regressão linear não pode ser considerado preditivo para umidade final da mandioca seca em função da temperatura de pré-cozimento, em razão do coeficiente de determinação de $70 \%$ e do desvio dos parâmetros da equação ser de até $29 \%$.

Com relação ao aspecto da amostra, foi observado visualmente que as amostras cozidas apresentam melhor aparência após a secagem, provavelmente como resultado do amolecimento do tecido e gelatinização do amido. Amostras cozidas em maiores temperaturas apresentaram visualmente maior grau de cozimento. Como a cinética de secagem dos produtos pré-cozidos a 70 e 100 ${ }^{\circ} \mathrm{C}$ não mostraram muita variação, a utilização da condição intermediária $\left(70{ }^{\circ} \mathrm{C}-6\right.$ minutos $)$ pode ser indicada para obtenção de produto com melhor resultado visual e com menor 
gasto de energia para aquecimento no prétratamento. Os resultados indicam, portanto, que o cozimento pode ser utilizado para melhorar a aparência do produto seco e possibilitar melhor controle de qualidade do produto.

\section{CONCLUSÃO}

Os resultados indicaram que o prétratamento de cozimento influenciou a cinética de secagem, com efeito significativo da temperatura. Quanto mais elevada a temperatura de cozimento maior foi $o$ resultado de umidade final em razão da redução da velocidade de secagem. O tempo de cozimento não teve efeito estatístico significativo. A utilização da condição intermediária $\left(70{ }^{\circ} \mathrm{C}-6\right.$ minutos $)$ mostrou melhor resultado visual quanto ao cozimento e a amostra seca

\section{NOMENCLATURA}

$\mathrm{X}$ umidade

$\mathrm{X} / \mathrm{X}_{0}$ umidade adimensional

Aw atividade de água

Ns não significativos

$\mathrm{T}$ temperatura $\left({ }^{\circ} \mathrm{C}\right)$

$\mathrm{T}$ tempo (min)

$\mathrm{s}$ segundos

SQ soma de quadrados

GL grau de liberdade

MQ média quadrática

Fcal F calculado

Ftab F tabelado

$\mathrm{R}^{2} \quad$ coeficiente de determinação

\section{REFERÊNCIAS}

ANTONIO, G. C. Influência da Estrutura Celular e da Geometria da Amostra na Taxa de Transferência de Massa do Processo de Desidratação Osmótica de Banana Nanica (Musa cavendishi) e de
Mamão Formosa (Carica papaya L.). 2002, 105p. Dissertação (Mestrado em Engenharia de Alimentos) - Universidade Estadual de Campinas, Campinas, 2002.

AOAC. Official Methods of Analysis. Washington: Association of Official Analytical Chemists, 1995.

ALVES, A.; CANSIAN, R. L.; STUART, G.; VALDUGA, E. Alterações na Qualidade de Raízes de Mandioca (Manihot Esculenta Crantz) Minimamente Processadas. Ciência e Agrotecnologia, v.29, p.330-337, 2005.

BEZERRA, V. S.; PEREIRA, R. G. F. A.; CARVALHO, V. D.; VILELA, E. R. Raízes de Mandioca Minimamente Processadas: Efeito do Branqueamento na Qualidade e na Conservação. Ciência e Agrotecnologia, v.26, p.564-575, 2002.

BOBBIO, F. O.; BOBBIO, P. A. Introdução à Química De Alimentos. São Paulo: Varela, 2001.

BOX, G. E. P.; HUNTER, W. C.; HUNTER, J. S. Statistics for Experimenters: an Introduction to Design, Data Analysis and Model Building. New York: John Wiley and Sons, 1978.

FELLOWS, P. J. Tecnologia do Processamento de Alimentos: Princípios e Práticas. Porto Alegre: Artmed, 2006.

DAMODARAN, S.; PARKIN, K. L.; FENNEMA, O. R. Química de Alimentos de Fennema, Porto Alegre: Artmed, 2010.

LOPES, F. J. Estudo do Fenômeno de Encolhimento na Secagem Convectiva de Abacaxi com Aplicação de Micro-ondas. 2013, 147p. Dissertação (Mestrado em Produção Vegetal) - Universidade Estadual do 
Norte Fluminense Darcy Ribeiro, Centro de Ciências e Tecnologias Agropecuárias. Campos dos Goytacazes, Rio de Janeiro, 2013.

MUJUMDAR, A. S. Drying Technology in Agriculture and Food Sciences. Science Publichers, Inc., USA. 2000.

NWOKOCHA L. N.; AVIARA, N. A.; SENAN, C.; WILLIAMS, P. A. A Comparative Study of Some Properties of Cassava (Manihot Esculenta, Crantz) and Cocoyam (Colocasia Esculenta, Linn) Starches. Carbohydrate Polymers, v.76, p.362-367, 2009.

ORSAT, V.: YANG, W.; CHANGRUE, V.; RAGHAVAN G. S. V. Microwave-Assisted Drying of Biomaterials. Trans IChemE, Part C, Food and Bioproducts Processing, v.85, p.255-263, 2007.

PEREIRA, N. R. Estudo da Aplicação de Micro-ondas na secagem de Bananas Tratadas Osmoticamente. 2007. Tese (Doutorado em Engenharia de Alimentos) Universidade Estadual de Campinas, São Paulo, 2007.

PEREIRA, N. R.; GODOI, F. C.; ROCHA, S. C. S. Drying of Starch Suspension in Spouted Bed with Inert Particles: Physical and Thermal Analysis of Product. Drying Technology, v.28, p.1288-1296, 2010.

PEREIRA, N. R.; SOARES, T. S.; GONÇALVES, L. T.; MUSSI, L. P.; FERREIRA, K. S. Influence of Cooking as a Pre-Treatment to Microwave Drying of Manioc Roots. In: 19th International Drying Symposium, 2014. Lyon, France. 2014

RAGHAVAN, G. S. V.; RENNIE, T. J.; SUNJKA, $\quad$ P. $\quad$ S.; ORSAT, V.;
PHAPHUANGWITTAYAKUL, W.; TERDTOON, P. Overview of New Techniques for Drying Biological Materials with Emphasis on Energy Aspects. Brazilian Journal of Chemical Engineering, v. 22, p.195-201, 2005.

SAJEEV, $\quad$ M. $S$; SREEKUMAR, J.; UNNIKRISHNAN, M; MOORTHY, S. N.; SHANAVAS, S. Kinetics of Thermal Softening of Cassava Tubers and Rheological Modeling of the Starch. Journal of Food Science and Technology, v.47, p.507-518, 2010.

TACO. Tabela Brasileira de Composição de Alimentos. Campinas, NEPA UNICAMP 2011.

VARNALIS, A. I. BRENNAN, J. G. MACDOUGALL D. B. A Proposed Mechanism of High Temperature Puffing of Potato. Part II. Influence of Blanching and Initial Drying on the Permeability of the Partially Dried Layer to Water Vapour. Journal of Food Engineering, v.48, p.369378, 2001.

\section{AGRADECIMENTOS}

Os autores agradecem à FAPERJ pelo apoio financeiro e ao CNPq, CAPES e UENF pelas bolsas de estudo associados a este trabalho. 